\title{
O REALISMO INTERNO CONFRONTADO COM "SEUS INIMIGOS"
}

\author{
Edna de Souza ALVES ${ }^{1}$
}

- RESUMO: Analisamos brevemente a perspectiva realista interna, proposta por Putnam, contrastando-a com as suas principais rivais: a realista metafísica e a relativista radical. Tomamos como ponto de partida o debate contemporâneo em que o realismo interno se encontra envolvido, em especial, o desafio que o relativismo extremo impõe à epistemologia contemporânea. Parece pacífico entre os filósofos que tal desafio não será superado pelo projeto clássico de buscas por certezas absolutas. A história da ciência já nos deu muitas evidências de que as teorias não são redes que captam a realidade em si. Mas, por si só, isso não implica que a nossa visão de conhecimento seja determinada simplesmente por aspectos temporais e espaciais, pelo sujeito falível e pelo contexto em que se encontra. Nesse cenário, são empreendimentos difíceis, mas merecedores de atenção, as tentativas, de filósofos como Putnam, de construir teorias que não desconsiderem a história nem abracem, ao mesmo tempo, o relativismo radical.

- PALAVRAS-CHAVE: realismo interno; realismo metafísico; relativismo; racionalidade; objetividade.

\section{Introdução}

Neste trabalho, apresentaremos uma caracterização do realismo interno proposto por Putnam, distinguindo a sua participação no debate filosófico contemporâneo entre o realismo e o anti-realismo. Faremos algumas reflexões sobre o realismo interno a partir do cenário crítico em que se encontra inserido, de modo a vislumbrar o futuro dos programas de pesquisas filosóficas.

1 Doutoranda em Filosofia pelo Programa de Pós-Graduação em Filosofia da Universidade de São Paulo-USP sob orientação de Caetano Ernesto Plastino. Artigo recebido em set/07 e aprovado em dez/07. 
Como corolário de nosso objetivo, serão consideradas algumas das críticas dirigidas ao realismo interno e as respostas de Putnam a esses ataques, em especial à acusação de que o seu realismo interno é, na verdade, uma forma de relativismo.

Inicialmente, apresentaremos respectivamente uma caracterização do realismo metafísico, do realismo interno e do relativismo radical. Mostraremos algumas diferenças e semelhanças que o realismo interno mantém em relação ao realismo metafísico e ao relativismo radical. Paralelamente, pretendemos examinar a capacidade do realismo interno de responder aos problemas que the são apresentados. Com isso, buscamos uma caracterização mais precisa da perspectiva internalista putnamiana, bem como de suas rivais. Em seguida, apresentaremos um pequeno balanço de algumas implicações do realismo interno. Na seqüência, à guisa de conclusão, consideraremos algumas balizas para um caminho aberto aos programas contemporâneos de pesquisa filosófica.

\section{1 - Realismo metafísico, realismo interno e relativismo radical: uma caracterização}

O realismo metafísico é uma doutrina tradicionalmente aceita na filosofia. Tal como freqüentemente entendido, o realismo metafísico é uma doutrina ontológica que se desvincula da epistemologia. Nessa perspectiva defendem-se em especial quatro teses. De acordo com a primeira, é inquestionável a existência de uma realidade completamente independente do sujeito. Essa realidade é constituída por objetos com propriedades intrínsecas a eles. De modo que, de acordo com a segunda tese, uma descrição verdadeira da realidade, do todo ou de alguma parte, deveria levar em consideração as propriedades inerentes a esses objetos que a constituem. A verdade, nesse contexto, de acordo com a terceira tese, é entendida como uma correspondência fiel aos objetos ou fatos como eles são em si mesmos. Isso leva à possibilidade de uma espécie de confrontação entre a realidade e as teorias pretensamente aplicadas a ela (visão do Olho de Deus): quarta tese realista metafísica. ${ }^{2}$

2 Apesar de filósofos contemporâneos, como Putnam (1981, p.49) e Richard Rorty (1980, p.12), atribuírem a essa perspectiva o comprometimento com as teses acima, essa caracterização não é incontroversa. Podemos verificar leituras distintas, como a de Hartry Field (1982) e Caetano E. Plastino (2000), que não aceitam tal caracterização, alegando que essas teses atribuídas ao realismo metafísico não são essenciais a essa doutrina e que é possível identificar na história pensadores ditos realistas metafísicos que não subscreveram a todas elas. A fim de mostrar a representatividade da caracterização do realismo metafísico acima, sugerimos (cf. Alves, 2005) que se pode destacar nos textos de Michael Devitt (1984) e Galileu Galilei (1983; 1999), pensadores normalmente citados como típicos realistas metafísicos, passagens em que se identifica a interdependência das teses em questão. Assim, pretendemos justificar a essencialidade de tais teses como caracterizadoras de uma postura realista metafísica, bem como confirmar a representatividade histórica dessa caracterização. 
O realismo interno, proposto por Putnam (1981, p.49-50), por sua vez, se contrapõe ao realismo metafísico. Assim, a partir da negação das teses características do realismo metafísico, Putnam apresenta a sua proposta positiva. De acordo com a perspectiva internalista putnamiana não há uma nítida cisão entre o sujeito e a realidade (primeira tese). Sujeito e realidade se constróem mutuamente. As descrições da realidade serão sempre as nossas descrições da realidade (segunda tese). Elas, admitidamente, incorporam elementos subjetivos. No internalismo não se pretende que possa existir a descrição verdadeira ou correta da realidade. As nossas descrições e teorias devem ser consistentes e se ajustar aos dados obtidos experiencialmente e ao nosso corpo teórico total. Nesse sentido, elas sofrem restrições empíricas e teóricas para serem racionalmente aceitas. Defende-se, assim, uma teoria coerentista da justificação. No entanto, Putnam não identifica 'verdade' com 'justificação' ou 'aceitabilidade racional'. A verdade, para ele, pode ser melhor entendida como a idealização da aceitabilidade ou justificação racional (terceira tese). Uma crença que fosse justificada em condições ideais, que passasse por todos os testes imagináveis e, ainda assim, fosse corroborada, que satisfizesse todos os critérios relevantes para ser aceita racionalmente como verdadeira seria, de fato, verdadeira. Embora não possamos atingir condições epistêmicas ideais, podemos, proveitosamente, imaginá-las e é isso que aprendemos a fazer na prática. Através da prática aprendemos a decidir entre acreditar na, ou negar a, verdade de uma crença em seu contexto. Putnam não pretende apresentar uma definição formal de verdade, apenas elucidar, informalmente, a complexidade dessa idéia. Com isso, pretende esclarecer alguns fenômenos relacionados às nossas práticas cotidiana e científica que envolve essa noção. Não dispomos de uma visão do Olho de Deus, como diz Putnam, mas dispomos de vários pontos de vista de pessoas reais que refletem, razoavelmente, suas descrições e teorias (quarta tese). Embora essa reflexão não esteja imune aos diversos interesses e propósitos envolvidos nas descrições e teorias propostas pelo sujeito, a racionalidade humana já provou ser capaz de garantir certa objetividade, também humana e suficiente. Apesar de seu caráter "antropocêntrico" (de serem profundamente interligadas com a nossa psicologia, de dependerem de nossa biologia e cultura, não sendo 'livres de valor'), a racionalidade e a objetividade já provaram ser suficientes. Para comprovar isso, basta olhar para o grande êxito da ciência (nosso modelo de procedimento racional), para a sua eficácia instrumental, sua coerência, sua abrangência, sua simplicidade funcional etc.

Uma das conseqüências marcantes desse viés epistemológico do internalismo é a sua aparente aproximação do relativismo. Por relativismo geralmente entende-se a doutrina segundo a qual, em pelo menos algumas áreas, a verdade é relativa ao ponto de vista do sujeito (no singular ou plural). 
O relativismo pode ser uma doutrina geral: sobre todo o conhecimento; ou uma doutrina mais particular: sobre o conhecimento em uma área específica, como a ciência, a moral e a estética. A sua formulação clássica, atribuída a Protágoras, é enunciada pelo célebre princípio segundo o qual "o homem é a medida de todas as coisas" (cf. o diálogo socrático de Platão, Teeteto). A crítica dos grandes pensadores gregos a essa forma de relativismo consistiu em elucidar o seu caráter auto-contraditório: se o relativismo é verdadeiro, então é falso. De acordo com a própria perspectiva relativista, o ponto de vista segundo o qual o relativismo é verdadeiro é apenas um dentre muitos outros pontos de vista possíveis e igualmente coerentes, tais como o de que o relativismo é falso. Contemporaneamente, encontramos uma diversidade de formulações do que seria o relativismo (tanto por parte dos partidários como dos oponentes do relativismo), por conseqüência, o debate epistemológico em torno do tema é muitas vezes obscurecido. Sendo assim, devemos circunscrever a abordagem relativista que subsidiará a nossa discussão. Como o conceito de verdade está estreitamente associado ao de conhecimento e racionalidade (por exemplo, sugere-se, em o Teeteto, que o conhecimento seja uma crença verdadeira justificada racionalmente), o relativismo cognitivo ou epistemológico conduz, ou pelo menos insinua, a relatividade do conhecimento e da racionalidade, assim como da verdade. Assim, encontramos a formulação do relativismo, segundo o qual, a partir de evidências históricas, se constata que nenhum conjunto de normas epistemológicas, como critérios de verdade e padrões de racionalidade, é metafisicamente privilegiado em relação a qualquer outro. Temos aqui o relativismo quanto à justificação do conhecimento. A objeção padrão ao relativismo (auto-refutação) também pode ser adaptada para ser empregada nesse caso. No entanto, isso não impede que alguns pensadores elaborem criticas às noções de 'fundamento do conhecimento', 'verdade objetiva e necessária', 'filosofia como tentativa de responder ao ceticismo', tais como concebidas pela filosofia tradicional. Por exemplo, para Rorty (1980), freqüentemente citado como um dos principais defensores contemporâneos de, pelo menos, alguns dos ideais relativistas, essas noções são, particularmente, um "produto do século XVII", que levou a filosofia a centrar-se na epistemologia. Essa imagem do século XVII da filosofia enquanto epistemologia além de estar muito "desgastada", longe de ser necessária, é opcional.

Para Rorty (1980, p.390), a filosofia centrada na epistemologia é apenas um "episódio na história da cultura européia". Daí advêm os traços do relativismo extremo que podem ser encontrados em parcelas de sua obra: não só as crenças mudam de cultura para cultura (relativismo cultural comumente aceito), mas também a racionalidade depende de cada cultura (relativismo epistemológico radical). 
Apesar de admitir, em seu sistema, que os padrões de racionalidade variam conforme o tempo e que as noções de justificação racional e verdade estão relacionadas, Putnam não deve ser confundido com um relativista radical. Isso porque ele não identifica a noção de verdade com as de justificação ou aceitabilidade racional. Putnam (1990), ao contrário de Rorty, reserva para a verdade um papel especial: preservar a objetividade humana (objetividade ainda em um sentido bastante tradicional), ser um conceito regulador que guia o (mas que, por outro lado, também é guiado pelo) desenvolvimento dos nossos padrões de racionalidade e justificação. Ele defende, em seu realismo humano, uma peculiar forma objetiva de verdade e de realidade, como já foi mencionado.

O relativismo radical de Rorty (1980), por sua vez, não dá margem a qualquer tentativa de preservação de alguma objetividade (no sentido tradicional) ao conhecimento. A "verdade", em sua perspectiva, é restringida à concordância com os padrões aceitos em uma determinada época e cultura. Para Rorty, falar de nossos pensamentos ou palavras como "verdadeiros" ou como "de acordo com os fatos", nada mais é do que "cumprimentar" a nós mesmos por nossas criações intelectuais. ${ }^{3}$

Na próxima seção, identificaremos algumas diferenças e semelhanças entre as perspectivas conflitantes aqui brevemente caracterizadas (o realismo metafísico, o realismo interno e o relativismo radical), ao apresentarmos alguns desafios propostos ao realista interno. Especial atenção será concedida à tentativa putnamiana de impor certa distância entre o seu realismo interno e o relativismo. Com isso, se revelarão, mais claramente, os contornos básicos dessas perspectivas em questão.

\section{2 - A face humana do realismo interno}

Tanto o realista metafísico como o realista interno e, curiosamente até mesmo, o relativista, pretendem que a sua doutrina seja a melhor explica-

3 Nos Philosophical Papers encontramos um Rorty mais moderado, mais preocupado com a questão da verdade, do que o Rorty de o Philosophy and the Mirror of Nature. As implicações dessa "moderação" para o sistema rortyiano como um todo, no entanto, são bastante discutíveis (cf. Alves, 2005): apresentar uma noção de verdade minimalista, não-relativista, quando se defende que o único critério para se saber se algo é verdadeiro é a justificação, que, por sua vez, é completamente dependente dos padrões culturais e temporais (ou seja, quando, segundo Putnam (2001,p.41), "com respeito ao conceito de justificação ele é um relativista explícito"), não faz de Rorty, na prática, menos relativista. Ademais, na perspectiva pragmatista, defendida por Rorty, quando uma distinção entre dois conceitos não faz diferença na prática, entende-se que essa distinção não tem qualquer sentido. Como a distinção entre as noções de verdade e justificação não faz diferença na prática, por conseguinte, seria uma distinção que não faz sentido e que, portanto, não deveria constar na agenda do filósofo. Assim, toda a retórica e a moderação na forma de usar as palavras que reconhecemos nas últimas obras de Rorty, bem como essa alusão a uma noção minimalista de verdade, não parece ser suficiente para afastá-lo do relativismo extremo que detectamos, mais explicitamente, em o Philosophy and the Mirror of Nature. 
ção da realidade (tal como cada um a entende). Todos eles concordam com Kant (cf. Crítica da Razão Pura) e, na verdade, com o senso comum e com a esmagadora maioria dos filósofos mais representativos, que é inaceitável uma doutrina segundo a qual a existência de mesas e cadeiras é colocada seriamente em dúvida.

Segundo Putnam (1987), a chave para executar o programa clássico de preservar o realismo do senso comum, evitando, ao mesmo tempo, "os absurdos e as antinomias do realismo metafísico" é adotar o realismo interno: "O realismo interno é, no fundo, exatamente a insistência em que o realismo não é incompatível com a relatividade conceitual. Pode-se ser um realista e um relativista conceitual." (p.17)

O fenômeno da relatividade conceitual é tipicamente identificável quando duas ou mais descrições equivalentes verdadeiras são incompatíveis a partir de perspectivas diferentes. Um dos exemplos utilizados por $\mathrm{Pu}$ tnam (1987, p.18-9) como ilustração do fenômeno da relatividade conceitual é o seguinte:

Considere 'um mundo com três indivíduos' [...], x1, x2, x3. Quantos objetos há neste mundo?

Bem, eu disse "considere um mundo com exatamente três indivíduos", não disse? Então não deve haver três objetos? [...]

[...] Mas há perfeitamente boas doutrinas lógicas que levam a resultados diferentes.

Suponhamos, por exemplo, que, como alguns lógicos poloneses, eu acredite que para cada dois particulares há um objeto que é a soma deles. (Esta é a suposição básica da 'mereologia', o cálculo das partes e todos inventado por Lezniewski.) Se ignoro, por um momento, o assim chamado 'objeto nulo', então acho que o mundo de três 'indivíduos' [...] realmente contém sete objetos [...]

Alguns lógicos poloneses diriam também que há um 'objeto nulo' que eles contam como uma parte de todo objeto. Se nós aceitarmos esta sugestão, e adicionarmos esse indivíduo (o chamarmos de $\mathbf{0}$ ), então diríamos que o mundo [...] contém oito objetos.

Apesar de a literatura apresentar muitos casos em que se verifica o fenômeno da relatividade conceitual, o realismo metafísico, segundo Putnam (1987, p.19) não pode reconhecer tal fenômeno. Isso porque tal fenômeno é incompatível com as teses centrais dessa perspectiva filosófica. A relatividade conceitual mostraria que não faz sentido falar do mundo como consistindo em uma "totalidade de objetos" independente da mente. Como sugere Putnam (1978, p.132), aceitar o fenômeno da relatividade conceitual implica aceitar pelo menos a participação do sujeito na construção dos objetos, mesmo que esta construção não seja uma construção tal como literalmente entendida. Como poderíamos considerar que teorias com ontologias dife- 
rentes são ambas verdadeiras se, previamente, não aceitarmos que o que consideramos como objeto depende em grande parte do sujeito, de seus aparatos perceptual e conceitual? A noção de objeto, o que se entende por objeto e uma possível contagem desses objetos, dependem do sujeito e não do mundo propriamente dito. À parte de uma nítida distinção didática, o ontológico está estreitamente vinculado ao epistemológico. Falar da existência de uma única descrição completa e verdadeira desse mundo independentemente do nosso aparato conceitual seria absurdo. Não existe a maneira correta de representar o mundo, uma maneira que é própria desse mundo. Nossas representações do mundo são sempre nossas representações. Existe mais de uma maneira correta ou verdadeira de descrever um objeto, isso é o que mostra o próprio fenômeno da relatividade conceitual.

Dessa perspectiva, a verdade, longe de ser exatamente uma correspondência com os fatos, mostrar-se-ia interna à perspectiva adotada. Não é apenas o mundo que determina o valor de verdade da proposição "Existem x objetos", mas também o esquema conceitual adotado. A verdade de uma proposição depende, dentre outras coisas, de sua coerência teórica, fato que mostra a insustentabilidade de uma perspectiva externalista, que defende a possibilidade de que, a partir de um ponto de vista do Olho de Deus, apreendamos o mundo como ele é em si mesmo, sem qualquer contaminação conceitual.

Putnam está perfeitamente consciente da aparente aproximação do realismo interno com o relativismo e da necessidade de reafirmar seu credo não-relativista (1987, p.17-8): "A relatividade conceitual soa como 'relativismo', mas não tem nenhuma das implicações do 'relativismo', como o 'não há verdade para ser descoberta... [ou] "verdadeiro" é apenas um nome para o que um grupo de pessoas pode concordar sobre'."

Esse ponto do pensamento de Putnam (que sugere uma aparente aproximação do realismo interno ao relativismo radical) é, possivelmente, aquele que mais suscita atenção e polêmica, seja por parte de seus críticos imediatos (aqueles que, como Devitt, defendem o realismo "tradicional"), como por parte daqueles que, por vezes, querem ver em Putnam um aliado a favor do relativismo (por exemplo, Rorty). A polêmica é compreensível. Isso porque as diferentes respostas "verdadeiras" para a pergunta "Quantos objetos há neste mundo?" podem propiciar duas explicações distintas. Por um lado, podem mostrar que a realidade depende, de alguma forma, do sujeito, se for focado o papel desempenhado pelo sujeito na "construção" da realidade. Por outro lado, podem significar apenas que o mundo admite interpretações diferentes, se for focado o papel desempenhado pelo mundo no processo cognitivo. Tanto o primeiro caso como o segundo trariam conseqüências indesejáveis ao realismo interno. Mas não devemos destacar apenas o papel do sujeito ou o do mundo no processo cognitivo, e sim, fazermos justiça a am- 
bos. Como sugere a conhecida metáfora utilizada por Putnam (1981, p.xi), "[...] a mente e o mundo constroem conjuntamente a mente e o mundo".

No primeiro caso (em que as diferentes respostas "verdadeiras" para a pergunta "Quantos objetos há neste mundo?" favorecem a explicação de que a realidade depende do sujeito), essas diferentes descrições verdadeiras do que se pretendia, pelo menos inicialmente, ser o mesmo mundo, ou seja, o fato de o mundo conter três objetos para João e sete para o lógico polonês, mostraria que o mundo para João é diferente do mundo para o lógico polonês. Nesse caso, não existiria qualquer coisa real sobre a qual se fala. O mundo, ou os mundos, seria puramente criação teórica. Não existiria qualquer realidade objetiva que pudesse ser descrita corretamente ou qualquer Verdade sobre a realidade que pudesse ser descoberta. O realismo interno seria, efetivamente, uma forma de idealismo/relativismo extremo. $\mathrm{O}$ que significaria que recairiam sobre si todas as críticas tecidas contra as perspectivas relativistas radicais, para o deleite de pensadores como Devitt. Por outro lado, para a satisfação de pensadores, como Rorty, isso significaria que o crescente movimento relativista teria arrebanhado mais um forte aliado: Putnam.

Já no segundo caso (em que a melhor explicação para a existência de diferentes respostas "verdadeiras" para a pergunta "Quantos objetos há neste mundo?" é a de que o mesmo mundo admite interpretações diferentes), o fato de o mundo (o mesmo mundo, real e independente) admitir interpretações diferentes é perfeitamente compatível com a perspectiva realista metafísica. Pois o realista metafísico não teria dificuldade em admitir que de acordo com certa interpretação, que considera determinados aspectos da realidade, o mundo seja descrito de uma maneira, ao passo que, considerando-se outros aspectos, poderíamos obter uma outra descrição tão correta como aquela. Sendo assim, Putnam não teria de forma alguma colocado o realista metafísico em uma situação embaraçosa ao listar casos em que ocorre o fenômeno da relatividade conceitual. Ao contrário, ele é que seria colocado em uma situação indesejável. Isso porque, além de fracassar em criticar o realismo metafísico, o realismo interno seria deixado em uma posição muito próxima à do realista metafísico, compartilhando, assim, das próprias dificuldades e equívocos inerentes a essa postura.

4 Como elucidaremos abaixo, em a peculiar abordagem realista interna da relação entre sujeito e realidade, em condições cognitivas adequadas o sujeito consegue ter acesso aos objetos que constituem a realidade, ao passo que, sem essas condições o objeto de cognição torna-se inacessível. A realidade, de certa forma, depende do sujeito e, ao mesmo tempo, constitui um fator objetivo da experiência. Isso explica porque em o realismo interno é coerente assumir que a realidade admite descrições ou teorias diferentes, não obstante, verdadeiras, sem, com isso, incorrer num relativismo extremo. 
Putnam, em resposta à primeira parte do desafio que lhe foi proposto, poderia continuar afirmando que a relatividade conceitual não implica, necessariamente, o "vale-tudo" do relativismo radical. Segundo Putnam (1987, p.20), do ponto de vista do realismo interno:

Uma vez que nós deixamos claro como estamos usando 'objeto' (ou 'existe'), a questão 'Quantos objetos existem?' tem uma resposta que não é, em absoluto, uma questão de 'convenção'. Essa é a razão pela qual eu disse que esse tipo de exemplo não serve de suporte para o relativismo cultural radical. Os nossos conceitos podem ser relativos culturalmente, mas a isso não se segue que a verdade ou falsidade de tudo que dissermos usando esses conceitos seja simplesmente 'decidida' pela cultura.

Jézio H. B. Gutierre (1993, p.83), destaca que essa proposta putnamiana não apenas sugere que possamos distinguir, com base em fundamentos racionais, entre alternativas boas e ruins, mas, sobretudo, que podemos ser objetivos dentro de um esquema conceitual.

Putnam (1981) acredita haver algo independente do sujeito que, de algum modo, nos faria perceber os objetos que percebemos. Algo que serviria de restrições às nossas teorias e descrições da realidade, apesar da dificuldade, ou melhor, da impossibilidade, de falarmos e até mesmo de imaginarmos esse algo, uma vez que, para isso, são envolvidos os esquemas internos ao sujeito. Esse algo seria os "objetos" na ausência de condições de objetivação que, por sua vez, são oferecidas pelo sujeito. Os objetos empíricos são "construídos" na presença de condições cognitivas, epistêmicas, adequadas.

Nesse sentido, Kevin Kelly, Cory Fuhl \& Clark Glymour (1994, p.133) estão corretos ao afirmar que Putnam incorpora em seu sistema filosófico "a distinção de Kant entre o mundo em si e o mundo da experiência". O mundo em si (independente do sujeito, incognoscível e inefável) não vem pré-dividido em indivíduos e relações distintos, porque isso depende do sujeito: o aparato perceptual e conceitual do sujeito é que o faz perceber e classificar os objetos, individualizando-os. O mundo da experiência, por sua vez, é o mundo tal como nos aparece, que percebemos por meio de nossos arcabouços perceptivo, representacional e conceitual.

Putnam (1981) defende o realismo do senso comum. Ele acredita, e a grande maioria de nós certamente também, na existência de "um mundo composto por mesas e cadeiras". Tanto é assim que nos comportamos como se existissem mesas e cadeiras. Pensamos e falamos a respeito de mesas e cadeiras. Acreditamos, pensamos e falamos a respeito de mesas e cadeiras que pertencem ao mundo empírico, que podem ser manipuladas, utilizadas, por nós. As nossas representações e descrições desses objetos serão sempre nossas e não uma representação e descrição de como elas são em si. E, se isso é assim, não é porque a coisa em si nos é inacessível (dada as nossas 
limitações), mas porque não faz sentido acreditar e falar da coisa em si. Como não faz sentido falar de objetos sem um esquema conceitual, assim, também não faz sentido falar de propriedades intrínsecas, aquelas que, supostamente, seriam as propriedades reais que as coisas tem em si mesmas. As dicotomias coisa em si/coisa para nós e propriedades intrínsecas/propriedades projetadas devem ser abandonadas. As coisas que percebemos, representamos e descrevemos são sempre "coisas para nós". As coisas para nós são simplesmente "coisas", não projeções. Conseqüentemente, não faz sentido falar em termos dessas dicotomias.

Quanto à segunda parte do desafio que lhe fora proposto, segundo Putnam (1987, p.20),

[...] a idéia de que há um ponto arquimediano, ou um uso de 'existe' inerente ao próprio mundo, do qual a questão 'Quantos objetos realmente existem?' faz sentido, é uma ilusão.

Se isso é correto, então pode ser possível ver como é que o que é, em algum sentido, o 'mesmo' mundo [...] pode ser descrito como consistindo em 'mesas e cadeiras' [...] em uma versão e como consistindo em regiões espaço-temporais, partículas e campos etc., em outras versões. Exigir que todas essas versões devam ser redutíveis a uma única versão é cometer o equívoco de supor que 'Quais são os objetos reais?' é uma questão que faz sentido independentemente de nossa escolha de conceitos.

Não há nada de errado em o senso comum visualizar uma mesa como um objeto sólido, como um objeto que consiste de matéria que, em sua maior parte, é rígida e o físico vê-la como consistindo em sua maior parte de espaço vazio. Assim como não há nada de errado em o cientista ora utilizar a teoria dos campos, ora a teoria das partículas, para descrever e explicar alguns fenômenos naturais. Todas essas podem ser maneiras diferentes e coerentes de falar da mesma realidade.

Putnam (1992, p.122) transcreve o desafio que Goodman - típico defensor do relativismo extremo - teria lhe proposto: "Bem, se você diz que essas duas maneiras de falar [utilizando a linguagem dos "campos" ou a das "partículas"] são ambas descrições da mesma realidade [um sistema físico qualquer], então descreva essa realidade como ela é, à parte desses modos de falar." A isso, responde Putnam (1992, p.122):

[...] por que alguém deveria supor que a realidade pode ser descrita independentemente de nossas descrições? E por que o fato de que a realidade não pode ser descrita independentemente de nossas descrições deveria levar-nos a supor que há apenas descrições? Afinal, de acordo com as nossas próprias descrições, a palavra "quark" é uma coisa e um quark é uma coisa absolutamente diferente.

[...] embora as nossas sentenças realmente "correspondam à realidade", no sentido de descrevê-la, elas não são simplesmente cópias da realidade. [...] nossa linguagem 
não pode ser dividida em duas partes, uma parte que descreve o mundo "como ele é de qualquer modo" e uma parte que descreve a nossa contribuição conceitual. Isso não significa que a realidade é oculta ou numenal; significa simplesmente que você não pode descrever o mundo sem descrevê-lo.

Isso significa que Putnam, por um lado, critica um certo tipo de independência da realidade em relação à mente, ao esquema conceitual do sujeito. Esse tipo de independência é aquele proposto pelo realista metafísico, segundo o qual há um mundo completamente independente do sujeito, no sentido de ser um mundo pronto a ser apenas descoberto pelo sujeito. Um mundo que divide a si próprio em objetos e propriedades em um único modo definido, fixo. Por outro lado, aceita um outro tipo de independência da realidade em relação à mente, ao esquema conceitual do sujeito. A realidade não é apenas e tão-somente uma criação das teorias. Do fato de a descrição do mundo variar, de acordo com a teoria adotada, não se segue que a teoria constrói, literalmente, o mundo.

Da mesma forma, existe um sentido de correspondência entre a realidade e os conceitos que utilizamos para descrevê-la que Putnam critica e outro que ele admite. As teorias correspondem à realidade no sentido de serem descrições da realidade tal como a percebemos, mas não no sentido, tradicionalmente entendido, de serem cópias fiéis da realidade tal como ela é em si mesma.

As discordâncias entre o realismo interno e o realismo metafísico, assim como aquelas entre o realismo interno e o relativismo radical, são, geralmente, bastante frisadas. Mas é importante chamar a atenção, como o fizemos, para o que essas perspectivas conflitantes (o realismo metafísico e o relativismo radical) têm em comum com o realismo interno. O que o realismo interno guarda de semelhante com o realismo metafísico é a crença de que, de fato, existe algo independente do sujeito, esse algo é a massa informe de $\mathrm{x} 1, \mathrm{x} 2$, x3 ou de $\mathrm{x} 1, \mathrm{x} 2, \mathrm{x} 3, \mathrm{x} 1+\mathrm{x} 2, \mathrm{x} 1+\mathrm{x} 3, \mathrm{x} 2+\mathrm{x} 3, \mathrm{x} 1+\mathrm{x} 2+\mathrm{x} 3$, bem como de qualquer outra descrição verdadeira. O que há no realismo interno de semelhante ao relativismo radical é a possibilidade de haver várias descrições verdadeiras do mundo, oriundas de nosso corpo conceitual e teórico, e não apenas uma descrição do Mundo.

Como já visto, o fato de o realismo interno apresentar alguma semelhança com o realismo metafísico não o coloca no mesmo barco dessa perspectiva. O mesmo pode ser dito em relação a seu vínculo com o relativismo radical. Assim, Putnam acredita ter superado os desafios que lhe foram colocados pelos realistas metafísicos e pelos relativistas radicais, firmando o realismo interno como uma perspectiva mais plausível do que as suas rivais, conforme esboçaremos na seqüência. 


\section{3 - A superioridade do realismo interno em relação aos seus inimigos}

Depois de indicarmos as respostas oferecidas por Putnam aos desafios que lhe foram propostos, o que tornou possível formularmos, paralelamente, uma caracterização mais precisa da posição putnamiana, passamos a examinar as razões que norteiam a crença de Putnam, subscrita por nós, na superioridade de sua proposta em relação as suas rivais.

Embora no sistema filosófico putnamiano seja aceita a existência de várias descrições verdadeiras do mundo, isso não levou Putnam (1981) a admitir, necessariamente, que o mundo depende literal e completamente do sujeito. Nesse sentido, não haveria apenas descrições, discursos, palavras, mas também algo independente do sujeito que serviria de restrições às nossas descrições e teorias da realidade. Foi possível também preservar o realismo do senso comum, em que os objetos familiares têm uma realidade objetiva para nós, evitando, assim, um relativismo extremo e com ele todos os seus problemas, considerados por Putnam inaceitáveis. Putnam (1992) diz que o relativismo rortyiano, como o dos franceses (Derrida e outros), é uma postura irresponsável. Isso porque permitiria todo tipo de "justificação" e atitude, sob a desculpa de estarem de acordo com certos padrões aceitos, por exemplo. ${ }^{5}$ Além disso, o sistema rortyiano, ainda conforme Putnam, partilha das auto-contradições características das perspectivas relativistas: apóia o seu discurso em argumentos racionais absolutos, apesar de dizer que a própria noção de racionalidade é relativa e que não pode haver quaisquer argumentos absolutos legítimos, negando, portanto, que os argumentos racionais tradicionais devam ser acatados.

Por outro lado, ao admitir o fenômeno da relatividade conceitual e objetividade puramente humana, Putnam livrou-se dos principais problemas inerentes às teses centrais da perspectiva realista metafísica. No que se refere à primeira tese realista metafísica, Putnam (1981) diz que, mesmo se ignorássemos as evidências contrárias à tese de que o mundo é completa-

5 Para Putnam (1992, p.132-133), o relativismo radical por permitir posturas intelectuais e práticas inaceitáveis é uma visão "perigosa". Em suas palavras,

[...] essa visão é perigosa porque fornece ajuda e conforto para extremistas (especialmente extremistas de uma inclinação romântica) de todos os tipos, tanto da esquerda quanto da direita. O século 20 testemunhou eventos horríveis, cuja responsabilidade é tanto da extrema esquerda quanto da extrema direita.

[... a irresponsabilidade filosófica de uma década pode tornar-se tragédia política do mundo-real de algumas décadas posteriores. Desconstrução sem reconstrução é irresponsabilidade. 
mente independente do sujeito, o realista metafísico não poderia sustentála de forma consistente com a sua doutrina como um todo, caso levasse em conta, por exemplo, fenômenos como o da relatividade conceitual. Não seria possível ao realista metafísico defender, por exemplo, a primeira tese e admitir, razoavelmente, ao mesmo tempo, que o mundo permite mapeamentos diversos e verdadeiros. Ao mundo independente da mente caberia apenas uma descrição verdadeira, aquela que levaria em conta as suas propriedades e relações intrínsecas, essenciais. O fenômeno da relatividade conceitual, por sua vez, implica que pode haver mais do que uma descrição verdadeira da realidade. A verdade ou falsidade das descrições e teorias dependeria do que se convenciona. Salvar a tese da independência do mundo em relação ao sujeito, fazendo do mundo algo inacessível ao sujeito, ou seja, sem que se defenda a existência e, mais do que isso, a possibilidade de se obter, a descrição verdadeira desse mundo, não serviria ao propósito completo e pretensioso do realista metafísico, isto é, alcançar a verdade, entendida como uma espécie de correspondência ao modo de ser do mundo. Por ser tão ambicioso, a ponto de querer defender a existência desse mundo completamente independente do sujeito, o realista metafísico acaba por perder tanto o Mundo tal como é em si como o nosso mundo familiar. Isso porque o único mundo real por ele concebido lhe seria inacessível.

A crítica à segunda tese realista metafísica está relacionada à anterior. Para Putnam (1981), não podemos descrever objetivamente (no sentido tradicional) o mundo como ele é em si, porque o único sentido de objetividade possível é o de objetividade humana. Falar de objetos que compõem o mundo só faz sentido se considerarmos que esses objetos dependem, de alguma maneira, dos esquemas perceptual, cognitivo e conceitual do sujeito. Os objetos não podem ser ao mesmo tempo independentes da mente e autoidentificantes. Desse modo, qualquer descrição que se pretenda da realidade envolve inputs humanos e, portanto, perspectivas. Não existe uma descrição que seja a única, completa e verdadeira descrição do mundo tal como ele é em si.

Disso se segue a crítica à terceira tese realista metafísica: a idéia da verdade como correspondência acurada à realidade. Não podemos selecionar uma única correspondência correta entre dois domínios se não tivermos acesso a ambos os domínios. A idéia de cadeia causal do tipo apropriada apresentada pelo realista metafísico para explicar tal relação de correspondência não é satisfatória. Pressupor a existência de uma espécie de relação de causalidade entre as palavras e os objetos, que explicaria, em última análise, a correspondência entre eles sem, no entanto, explicar satisfatoriamente a natureza dessa relação de causalidade, parece simplesmente pressupor aquilo que está em questão. Além disso, a própria idéia de colocar cada pensamento ou palavra em uma relação de correspondência com os 
objetos como eles são em si mesmos carece de sentido. Isso porque o mundo dos objetos como eles são em si mesmos (o mundo numenal de Kant) não é dividido em objetos. É o sujeito quem, através de seus esquemas perceptual, cognitivo e conceitual recorta o mundo em objetos.

No que concerne à quarta tese realista metafísica, Putnam (1981) diz ser impossível olhar para a realidade, avaliá-la e descrevê-la, de um ponto de vista externo, privilegiado, o ponto de vista do Olho de Deus. Isso porque não podemos nos desfazer dos nossos arcabouços perceptual e teórico para olhar, avaliar e descrever a realidade, pois a existência desta já depende, de um certo modo, do arcabouço cognitivo do sujeito. Mas o realismo metafísico precisa apelar para uma visão do Olho de Deus a fim de garantir a objetividade metafísica que lhe é tão cara.

Nesse sentido, Putnam considera o realismo interno uma alternativa plausível entre o realismo metafísico e o relativismo radical. Na seqüência procuramos esboçar o que está envolvido na admissão da perspectiva internalista proposta por Putnam.

\section{Considerações finais}

Putnam (1992) procura apontar criticamente vários problemas inerentes ao relativismo radical. Também tenta mostrar a diferença importante existente entre essa perspectiva e o seu realismo interno. Apesar disso, parece se aproximar demais do relativismo, quando analisado o teor de suas respostas a questões como as seguintes: Como podemos estar certos de poder distinguir de fato entre alternativas boas e ruins? Que tipo de objetividade pode nos ser assegurada dentro de nossos esquemas conceituais? Como algumas visões diferentes da realidade são verdadeiras e outras não? Como alguns juízos de valor são razoáveis e outros não? Questões como essas ilustram a dificuldade de Putnam em manter um distanciamento significativo do relativismo.

As respostas usuais de Putnam a essas questões serão discriminadas nos quatro itens abaixo:

(1) Podemos distinguir as alternativas boas das ruins porque seguimos os padrões de aceitabilidade racional vigentes. Eles podem não ser perfeitos e imutáveis, mas são tudo o que temos e já provaram ser suficientes. Além disso, um realista metafísico, por exemplo, também deve se guiar pelos padrões de aceitabilidade vigentes. A despeito de suas pretensões, ele não tem acesso à Verdade, nem pode estar certo de aproximar-se dela.

(2) A objetividade que nos pode ser assegurada é a única possível, a única disponível, para seres com a nossa natureza: a objetividade humana. 
(3) Não existe a visão verdadeira da realidade. Visões diferentes da realidade podem ser verdadeiras. Isso não significa que todas as visões possíveis da realidade sejam verdadeiras. Existem restrições teóricas e empíricas que filtram as visões mais adequadas da realidade. Diferentes visões do mundo podem ser verdadeiras, mas nem todas as visões do mundo são apropriadas.

(4) Do mesmo modo que as teorias para serem aceitas passam por restrições, tendo que obedecer a padrões de aceitabilidade racional vigentes, os juízos de valor, para serem considerados razoáveis, devem obedecer aos padrões de justificação aceitos.

Paralelamente ao distanciamento que impõe entre sua posição e o relativismo extremo, Putnam também procede à discriminação da superioridade do realismo interno sobre o realismo metafísico. Ao contrário deste último, o realismo interno abandona a idéia do conhecimento enquanto tentativa de espelhar a realidade e a busca da verdade absoluta. Com isso, o realismo interno livra-se das dificuldades de realizar e justificar tais empreendimentos, ao que parece, intransponíveis. Além disso, ao fechar a lacuna entre objeto do conhecimento e sujeito conhecedor - explicando, sem o auxílio de uma teoria mágica, o acesso do último ao primeiro - muitas formas de ceticismo, irracionalismo e relativismo são evitadas pelo realista interno, tarefa que o realista metafísico, a despeito de suas pretensões, não realiza satisfatoriamente. No tocante ao questionamento cético, o realista interno pode plausivelmente responder que o conhecimento (humano) é possível. Não termos acesso ao mundo noumenal, o mundo das coisas em si, completamente independente do sujeito (isso porque só faz sentido falar de conhecimento a partir das possibilidades cognitivas humanas). Mas temos acesso ao mundo empírico, ao mundo tal como nos aparece e podemos conhecê-lo.

No que concerne ao irracionalismo, o realismo interno assegura um lugar para a razão no processo cognitivo. O realista interno aposta na possibilidade de termos crenças racionais e métodos racionais na ciência. As escolhas que fazemos, por exemplo, entre duas teorias científicas, não são algo aleatório ou puramente subjetivo. Elas obedecem ao padrão de justificação racional vigente.

Com base em nossa análise das vantagens e dificuldades do realismo interno, ousemos considerar algumas balizas para um caminho aberto aos programas contemporâneos de pesquisa filosófica: o brevíssimo contraste (acima) do realismo interno com seus opositores mais óbvios - o realismo metafísico, o relativismo, o ceticismo e o irracionalismo, - evidentemente não evidencia sua "vitória" sobre eles (como se alguma vitória definitiva fosse obtenível em filosofia), mas, ainda assim, sedimenta um quadro favo- 
rável à teoria de Putnam. Certamente, o debate envolvendo as perspectivas realista metafísica, realista interna e relativista radical que procuramos "retratar" pertence a um quadro de discussões muito mais amplo e complexo do que apresentamos. Ainda assim, acreditamos que o programa internalista, como via intermediária, possa ainda empunhar ideais caros à tradição filosófica ocidental.

De fato, as imagens da realidade e dos processos cognitivos previstos para a captação dessa realidade apresentados no sistema putnamiano são coerentes com um "propósito maior": a tentativa louvável e heróica de assegurar à filosofia o seu papel tradicional de instrumento crítico, racional, para lidar com questões fundamentais para o ser humano.

\section{Agradecimentos}

Este artigo resulta de minha pesquisa de mestrado, realizada na Faculdade de Filosofia e Ciências da UNESP de Marília-SP com apoio financeiro da FAPESP. Agradeço a essas instituições pelas condições de trabalho que me foram oferecidas. Discuti com muitas pessoas o conteúdo deste artigo para poder agradecer a cada uma delas individualmente, sem cometer terríveis esquecimentos. Porém, gostaria de agradecer, em especial, ao Professor Dr. Jézio Hernani Bomfim Gutierre, da FFC - UNESP/Marília-SP, que me orientou, de forma inestimável, na pesquisa de mestrado e que, no entanto, não pode ser responsabilizado pelas ingenuidades e equívocos contidos na dissertação, tampouco neste artigo. Gostaria de expressar meu agradecimento também ao Professor Dr. Caetano Ernesto Plastino, da FFLCH - USP, atual orientador, pelo incentivo, pela leitura cuidadosa deste artigo e pelos úteis comentários e sugestões que fez.

ALVES, Edna de Souza. Internal realism in front of "his ennemies". Trans/Form/ Ação, (São Paulo), v.30(2), 2007, p.75-91.

- ABSTRACT: Our investigation on Hilary Putnam's internal realist perspective (internalism) traces parallels and identifies differences between Putnam's ideas and their antipodes: metaphysical realist (externalism) and radical relativist. Our research has focused upon the contemporary debate in which it is inserted, particularly, upon the challenge that radical relativism to impose on contemporary epistemology. Such challenge will not be surmounted through classical project to find absolute certainties. The history of science to point out that theories are not nets that to catch the reality as it is in itself. But this do not to imply that our view of knowledge are only determined for contingent aspects. In this scenery are 
hard enterprise but it is worthy-while to take into account efforts of philosophers as Putnam to propose a via media.

- KEYWORDS: internal realism; metaphysical realism; relativism; racionality; objectivity.

\section{Referências bibliográficas}

ALVES, E. S. O realismo interno e seus inimigos. 2005. Dissertação (Mestrado) - Faculdade de Filosofia e Ciências, Universidade Estadual Paulista - UNESP, Marília, 2005.

DEVITT, M. Realism and truth. Princeton, New Jersey: Princeton Universidade Press, 1884.

FIELD, H. "Realism and Relativism". The Journal of Philosophy, v. 79, p.553-67, 1982.

GALILEI, G. "Carta a Cristina de Lorena". Tradução de C. A. Ribeiro do Nascimento. Cadernos de História e Filosofia da Ciência 5, p.91-123, 1983.

O Ensaiador. Tradução de H. Barraco.São Paulo: Nova Cultural, 1999.

GUTIERRE, J. H. B. Transcendental Idealist Motifs in Contemporary Epistemology: Some Parallels between Kuhn, Putnam, and Kant. 1993. Tese (Doutorado) Corpus Christi College University of Cambridge, Cambridge, 1993.

KANT, I. Crítica da razão pura. In: Crítica da razão pura e outros textos filosóficos. Tradução de V. Rohden. São Paulo: Abril Cultural, 1974. (Os Pensadores).

KELLY, K.; FUHL, C.; GLYMOUR, C. "Reliability, Realism, and Relativism". In: CLARK, P.; HALE, B. (Eds.). Reading Putnam. Cambridge, Oxford: Blackwell, 1995.

PLASTINO, C. E. "Realismo metafísico e relatividade conceitual". Cognitio. São Paulo, n. 1, p.79-93, 2000.

PLATÃO. Teeteto ou da ciência. Tradução de F. Melro. Lisboa: Editorial Inquérito, s.d.

PUTNAM, H. Meaning and Moral Sciences. London: Routledge \& Kegan Paul, 1978. Reason, Truth and History. Cambridge: Cambridge University Press, 1981.

The Many Faces of Realism. La Salle: Open Court, 1987.

Realism with a Human Face. Edited and introduces by J. Conant. Cambridge: Harvard University Press, 1990.

. Renewing Philosophy. Cambridge: Harvard University Press, 1992. 2001.

Enlightenment and Pragmatism. Amsterdam: Koninklijke Van Gorcum,

RORTY, R. Philosophy and Mirror of Nature. Oxford: Blackwell, 1980.

Objectivity, Relativism, and Truth. Cambridge: Cambridge University Press, 1991.

Truth and Progress. Cambridge: Cambridge University Press, 1998. 